\title{
Achieving selectivity in porphyrin bromination through a DoE-driven optimization under continuous flow conditions
}

\author{
Paolo Zardi ${ }^{1}$ (D) $\cdot$ Michele Maggini $^{1}$ (D) $\cdot$ Tommaso Carofiglio $^{1}$ (D) \\ Received: 9 October 2020 / Accepted: 24 November 2020 / Published online: 14 December 2020 \\ (C) The Author(s) 2020
}

\begin{abstract}
The post-functionalization of porphyrins through the bromination in $\beta$ position of the pyrrolic rings is a relevant transformation because the resulting bromoderivatives are useful synthons to covalently link a variety of chemical architectures to a porphyrin ring. However, single bromination of porphyrins is a challenging reaction for the abundancy of reactive $\beta$-pyrrolic positions in the aromatic macrocycle. We herein report a synthetic procedure for the efficient preparation of 2-bromo-5,10,15,20tetraphenylporphyrin (1) under continuous flow conditions. The use of flow technology allows to reach an accurate control over critical reaction parameters such as temperature and reaction time. Furthermore, by performing the optimization process through a statistical DoE (Design of Experiment) approach, these parameters could be properly adjusted with a limited number of experiments. This process led us to a better understanding of the relevant factors that govern porphyrins monobromination and to obtain compound $\mathbf{1}$ with an unprecedent $80 \%$ yield.
\end{abstract}

Keywords Bromination $\cdot$ Porphyrin synthesis $\cdot$ Design of experiment $\cdot$ Continuous flow

\section{Introduction}

Porphyrins and related compounds are a class of macrocycles that play a leading role in catalysis, [1-3] molecular recognition, [4-6] energy conversion [7] and photomedicine. [8, 9] Their remarkable optical and electrochemical properties can be modulated by a careful choice of peripheral substituents or by metalation of the inner core. Covalent linking of porphyrins to a wide variety of systems, such as carbon nanostructures [10] or biopolymers, [11-13] is commonly exploited to obtain functional materials. Peripheral functionalization may also be used to create light harvesting systems [14]. For

Article Highlights -A new methodology for the synthesis of a useful bromoporphyrin building block.

-Employment of continuous flow technology to enhance the selectivity in porphyrins single bromination.

-Use of Design of Experiment, an efficient statistical approach for reactions optimization yet underexploited in research laboratories.

Paolo Zardi paolo.zardi@unipd.it

1 Dipartimento di Scienze Chimiche, Università degli Studi di Padova, Via Marzolo 1, 35131 Padova, Italy instance, zinc porphyrins substituted at the $\beta$-pyrrolic position with groups bearing an extended $\pi$-system are known as a highly performing class of photosensitizers employed for Grätzel solar cells. [15] A convenient synthetic route to these compounds relies in the derivatization of meso-tetraaryl porphyrins through a two-step process in which the initial monobromination of a pyrrole moiety is followed by a crosscoupling reaction to achieve the desired functionalization. [16] Porphyrins mono-bromination is a reaction with an inherent poor selectivity for the simultaneous presence of eight available pyrrolic positions. Also, purification is an important issue, because the chromatographic separation of monobromo porphyrins from the starting material and/or from polybrominated adducts is hampered by their very similar retention factors. This often translates into a limited isolated yield for the monoadduct. For this reason, some authors propose the direct use the unpurified bromoporphyrins for further synthetic steps [17] since the final functionalized porphyrins is easier to separate, although this means a consistent production of waste materials.

In view to develop the synthesis of precisely designed porphyrins through scalable and sustainable methodologies, we implemented the bromination step with flow chemistry technology. [18] In particular, the improved mixing efficiency and heat transfer can be beneficial to the reaction selectivity. [19] 
For instance, the selective mono-bromination at the benzylic position of substituted toluene species was successfully achieved under continuous flow conditions. [20-22]. Despite the potential of continuous flow processing there are, to the best of our knowledge, only a few reports on their use for porphyrin synthesis. [23, 24] Even more surprisingly, there are no reports concerning continuous flow post-synthetic functionalizations of porphyrins.

In order to maximize the mono-bromination selectivity, it is necessary to finely tune the key reaction parameters; however, an accurate control of temperature and reaction time is difficult to achieve in batch systems. Up to now, the best results were achieved by a very slow addition of the brominating agent to the starting porphyrin that gave the monobromo derivative in $78 \%$ isolated yield on a $60 \mathrm{mg}$ scale. However, the same value dropped to $64 \%$ when the reaction was carried out on a gram-scale. [25]. On the other hand, continuous flow processes can be efficiently scaled up in an effortless way or with minimal changes in the reaction settings.

We investigated the selectivity in porphyrin monobromination by means of flow chemistry with the aid of the DoE statistical approach. DoE allows to optimize a reaction by modelling the response (e.g. yield) across the multiple variation of the relevant factors within a given "reaction space". [26] This approach stands in contrast with the more popular OVAT (one variable at a time) strategy. However, the significant advantages in employing a DoE methodology can be found in the limited number of experiments required to reach the final result and in the reliable optimum conditions derived from the statistical model. [27, 28] Moreover, DoE provide useful information by quantifying the effect of the variation of single factors, or factors combinations, on the product yield. Thanks to this underexploited strategy, we could identify the key reaction parameters, increasing the yield of 2-bromo5,10,15,20-tetraphenylporphyrin (1) up to $80 \%$.

\section{Results and discussion}

The single bromination at the pyrrolic $\beta$-position of mesotetraphenyl porphyrin (2) is generally carried out with NBS as the halogen source (Scheme 1). The inherent difficulties of this transformation were discussed above and consist in a delicate balance between the efficient conversion of the starting material and the generation of polybrominated byproducts.

We started this study by considering the conventional batchwise synthesis with two different protocols reported in the literature. The parent methodology reported by Callot [29] consists in refluxing a chloroform solution containing NBS and compound 2 . Zhang et al. improved this procedure by using pyridine as an additive and a slow addition of an NBS excess. [25] To the best of our knowledge, the latter is the strategy that gives the highest yield $(78 \%)$. We repeated the Zhang methodology by a dropwise addition over $3.5 \mathrm{~h}$ of an NBS solution in chloroform to a refluxing chloroform/ pyridine mixture containing 2 . After quenching the reaction, HPLC analysis of the crude mixture showed a composition of $72 \%$ of 1, 5\% unreacted 2 and $23 \%$ of a mixture of dibrominated porphyrins, confirming the literature data. On the other hand, we observed also a consistent amount of dibrominated byproducts, reasonably due to excess NBS (3 equivalents with respect to 2 ). Since the presence of polybrominated porphyrins hampers the purification of monobromo derivative, the additive-free Callot approach was pursued under continuous-flow conditions.

To this end, we used a Vapourtec R-Series modular flow system (the set-up is illustrated in the Supporting Information), in which two chloroform streams, containing 2 and NBS respectively, were mixed and flowed through a heated coil reactor. An in-line back-pressure regulating valve (BPR) allowed us to carry out the bromination at a temperature significantly higher than the chloroform boiling point. The reaction mixture was collected in a stirred flask containing an aqueous $\mathrm{Na}_{2} \mathrm{CO}_{3} / \mathrm{Na}_{2} \mathrm{~S}_{2} \mathrm{O}_{3}$ solution to quench unreacted NBS before HPLC analysis. This automated and reproducible flow system prompted us to perform reaction parameters screening and optimization by using the DoE approach. For this purpose, a set of experiments is planned following a given design, then the results are fitted in a mathematical model to predict the conditions for yield maximization. This approach is particularly convenient for the monobromination of compound 2, with the aim to find the sweet spot where an efficient conversion of the starting porphyrin occurs without an excessive formation of polybrominated byproducts.

In order to build the factorial design, three reaction parameters were chosen to be optimized; namely, temperature (T), residence time (Rt) and NBS equivalents (eq). Afterwards, the upper and lower limits of the three factors must be set in order to individuate the reaction space for the DoE analysis. To this
Scheme 1 Porphyrin 2 bromination with NBS<smiles>C1=Cc2nc1c(-c1ccccc1)c1ccc([nH]1)c(-c1ccccc1)c1nc(c(-c3ccccc3)c3ccc([nH]3)c2-c2ccccc2)C=C1</smiles><smiles>BrC1=CC(/C(c2ccccc2)=c2/ccc(=C(c3ccccc3)c3ccccc3)[nH]2)=N/C1=C(\c1ccccc1)c1ccc(/C(=C2/C=CC(/C=C\c3ccccc3)=N2)c2ccccc2)[nH]1</smiles>

di-brominated isomers 
aim, we performed some preliminary tests (see Supporting Information). At first, we investigated the reactions with a low residence time $(10 \mathrm{~min})$, the temperature ranging from $60{ }^{\circ} \mathrm{C}$ (close to chloroform boiling point at ambient pressure) to $150{ }^{\circ} \mathrm{C}$ (the upper temperature limit of the employed reaction system) and a stoichiometric amount of NBS (1 equivalent). We started to observe an appreciable $25 \%$ conversion of the starting material when two streams of chloroform containing 2 and NBS respectively were mixed at $100{ }^{\circ} \mathrm{C}$. By setting the temperature up to $140^{\circ}$ the conversion increased to 60 $70 \%$ but also the formation of polybrominated products was detected to a major extent ( $>10 \%)$. Also increasing the NBS amount up to 3 equivalents was detrimental to the monobromination selectivity even at mild conditions $\left(100{ }^{\circ} \mathrm{C}\right.$ and $10 \mathrm{~min}$ residence time, see Supporting Information), in contrast with the reported Zhang methodology.

With this preliminary information, the three factors $\mathrm{T}, \mathrm{Rt}$ and NBS equivalents were set in the respective ranges of 100 $140{ }^{\circ} \mathrm{C}, 10-40 \mathrm{~min}$ and $1-2$ equivalents. Once the factors levels were assessed, we could proceed to the DoE optimization by building a full factorial design of 11 experiments composed by eight corner points and three center points (Entries 1-11 of Table 1). As observed in the preliminary experiments, a high reaction temperature ensures a higher conversion of the starting material but we observed a drop in selectivity with respect to the reactions carried out at low T. Interestingly, the experiments performed at the center points conditions (Table 1, Entries 9-11) already exhibit a yield in the desired product comparable to the one reported by Zhang et al. The resulting yield in the mono-brominated product $\mathbf{1}$ was considered as the response parameter. By using the Minitab Statistical Software, the experimental data were fitted into a model through a multiple linear regression.

The data fitting gave an $\mathrm{R}^{2}$ of 0.999 ; thus, the model can nicely explain the response variation. The coded coefficients for the parameters in the regression equation are represented in Fig. 1 and were all found statistically significant with a confidence interval of 0.95 . The most influential contribution to porphyrin 1 yield variation were given by Rt and the twoway interaction between Rt and T. It is worth to mention that a poor influence was acknowledged to the NBS amount in the range between 1 and 2 equivalents. Each one of the three factors (T, Rt, eq) has a positive coefficient, but negative effects were found for all two-ways interactions ( $T * R t$, eq*Rt and eq*T). For instance, this points out that while a longer residence time can lead to a better yield in porphyrin $\mathbf{1}$, the simultaneous increase of both $\mathrm{T}$ and $\mathrm{Rt}$ has a negative impact.

The factorial design revealed the most influential parameters for the maximization of the monobromination yield. However, the software detected the presence of curvatures in the response surface. Therefore, the prediction of the optimal reaction conditions would be inaccurate if simply based on a linear model. In order to better describe the yield variance, a
Table 1 Experiments performed for the response optimization. ${ }^{\mathrm{a}}$ Determined by HPLC. ${ }^{\mathrm{b}}$ Ratio between yield and conversion. ${ }^{\mathrm{c}}$ Average values over three identical runs

\begin{tabular}{|c|c|c|c|c|c|c|c|}
\hline Entry & Run & $\begin{array}{l}\text { Factor } 1 \mathrm{~T} \\
\left({ }^{\circ} \mathrm{C}\right)\end{array}$ & $\begin{array}{l}\text { Factor } 2 \mathrm{Rt} \\
(\mathrm{min})\end{array}$ & $\begin{array}{l}\text { Factor } \\
3 \text { eq }\end{array}$ & $\begin{array}{l}\text { Conversion }^{\mathrm{a}} \\
(\%)\end{array}$ & $\begin{array}{l}\text { Response1 } \\
\text { Yield }^{\mathrm{a}}(\%)\end{array}$ & $\begin{array}{l}\text { Response } 2 \\
\text { Selectivity } \\
(\%)\end{array}$ \\
\hline 1 & \multirow[t]{8}{*}{ corner points } & 100 & 10 & 1.0 & 25 & 21 & 82 \\
\hline 2 & & 100 & 10 & 2.0 & 32 & 30 & 94 \\
\hline 3 & & 100 & 40 & 1.0 & 70 & 68 & 97 \\
\hline 4 & & 100 & 40 & 2.0 & 83 & 73 & 88 \\
\hline 5 & & 140 & 10 & 1.0 & 57 & 54 & 96 \\
\hline 6 & & 140 & 10 & 2.0 & 72 & 62 & 86 \\
\hline 7 & & 140 & 40 & 1.0 & 60 & 52 & 86 \\
\hline 8 & & 140 & 40 & 2.0 & 99 & 45 & 45 \\
\hline 9 & \multirow[t]{3}{*}{ center points } & 120 & 25 & 1.5 & 85 & 77 & 91 \\
\hline 10 & & 120 & 25 & 1.5 & 88 & 77 & 87 \\
\hline 11 & & 120 & 25 & 1.5 & 82 & 78 & 95 \\
\hline 12 & \multirow[t]{6}{*}{ axial points } & 120 & 40 & 1.5 & 94 & 75 & 80 \\
\hline 13 & & 120 & 10 & 1.5 & 35 & 34 & 99 \\
\hline 14 & & 140 & 25 & 1.5 & 82 & 69 & 84 \\
\hline 15 & & 100 & 25 & 1.5 & 55 & 49 & 91 \\
\hline 16 & & 120 & 25 & 1.0 & 68 & 67 & 99 \\
\hline 17 & & 120 & 25 & 2.0 & 82 & 75 & 92 \\
\hline 18 & $\begin{array}{l}\text { optimized } \\
\text { conditions }\end{array}$ & 119 & 30.6 & 1.5 & $93 \pm 0.4^{\mathrm{c}}$ & $80 \pm 1.2^{\mathrm{c}}$ & $86 \pm 3.6^{\mathrm{c}}$ \\
\hline
\end{tabular}


Fig. 1 Coded coefficients from the multiple linear regression performed on the results of the factorial design

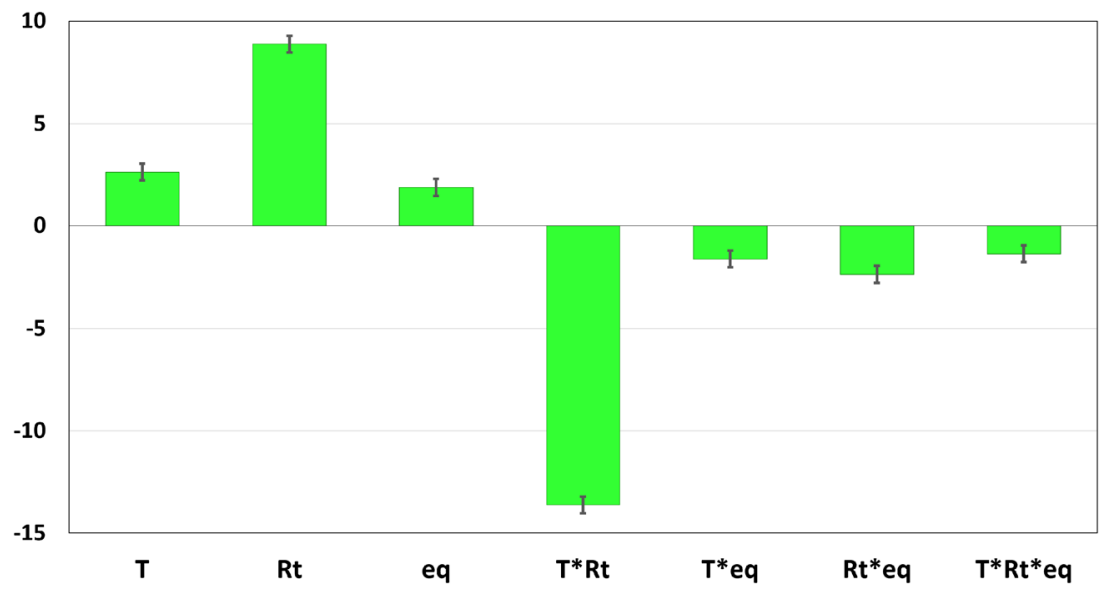

more detailed central composite design (CCD) (Fig. 2) was constructed by adding six additional experiments as axial points (Table 1 entries $12-17$ ) to the previous design. The so-obtained data were fitted through a multiple quadratic regression. The new model fitted reasonably with the experimental data and gave an $\mathrm{R}^{2}$ of 0.919 . The coefficients obtained from the quadratic regression are represented in Fig. 3. Considering a confidence interval of 0.95 , the coefficients associated with the NBS equivalents parameter was found not statistically significant and therefore excluded from the quadratic model. The central value of 1.5 NBS equivalents was kept constant while $\mathrm{T}$ and Rt were adjusted in order to maximize the $\mathbf{1}$ yield. The results of the prediction based on this model are pictured in the yield contour plot in Fig. 4a.

A similar CCD analysis was performed also considering the selectivity values reported in Table 1 as the response factor (the results of the multiple quadratic regression are reported in detail in the Supporting information). A plot of the predicted selectivity based on Rt and $\mathrm{T}$ variation with a constant number of NBS equivalents of 1.5 is represented in Fig. 4b. The comparison of the yield and selectivity plots reveals that the respective maxima are located in different areas. In fact, it

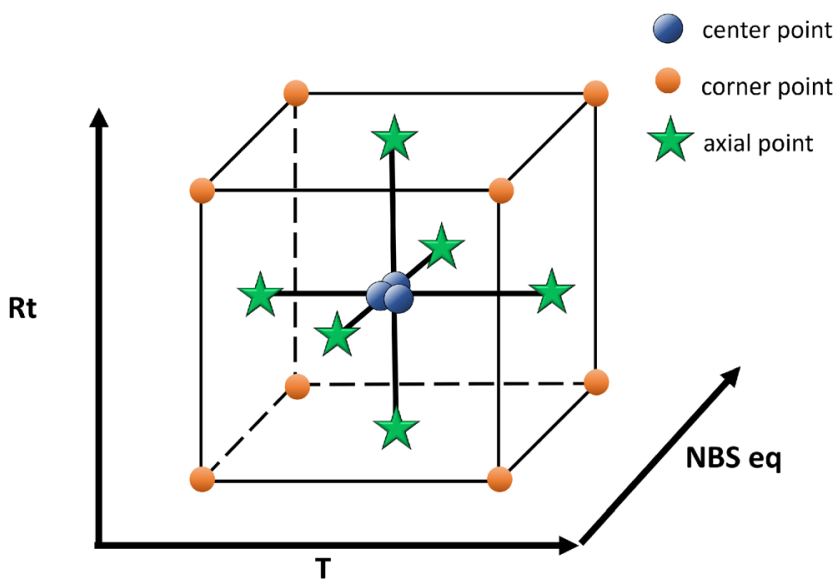

Fig. 2 Graphical representation of the CCD employed for the response surface analysis appears that the selectivity is maximized either at high residence time and low temperature or vice versa. On the other hand, the yield plot in Fig. 4a shows a well-defined area (marked in dark blue in the plot) that indicates the optimal Rt and $\mathrm{T}$ values where the monobromination yield is over 75\%. As observed in Fig. 4b, the predicted selectivity for the same Rt and $\mathrm{T}$ values is still high and ranges between 85 and $90 \%$. The optimal settings predicted in the contour plot in Fig. 4a were therefore employed to investigate the monobromination of 2 . Three runs were performed (Table 1 entry 18) at these conditions obtaining an average yield in $\mathbf{1}$ of $80 \%$, while compound $\mathbf{2}$ and dibrominated side-products were detected at $7 \%$ and $13 \%$ respectively.

With the optimized conditions in hand, the reaction was performed on a $150 \mathrm{mg}$ scale, which is a size comparable to the typical amounts of porphyrin compound usually employed for post-synthetic functionalization reactions in research laboratories. The HPLC analysis of the chloroform solution collected at the outlet of the flow system gave an $82 \%$ yield in porphyrin 1 and therefore a productivity of $22 \mathrm{mg} / \mathrm{h}$ was obtained by using a $10 \mathrm{~mL}$ coil reactor. After chromatographic purification, the desired pure product was isolated in a $73 \%$ yield.

In conclusion, we reported a continuous flow methodology for the selective monobromination of meso-tetraphenylporphyrin. A combined approach with an automated flow reactor and a DoEdriven optimization allowed us to enhance the compound 1 productivity with respect to the reported methodologies. This achievement relied in the precise control of the key parameters (such as the temperature and residence time) given by a continuous flow system and in their fine-tuning thanks to the statistical data treatment. With respect to the best existing methodology, this brought to a moderate improvement in the monobromination yield to $80 \%$ but other major advancements were achieved. Beside the intrinsic enhanced safety of using an aggressive brominating agent in a controlled environment, we reported a consistent decrease of the reaction time (30 min residence time versus $3.5 \mathrm{~h}$ of dropwise 
Fig. 3 Coded coefficients from the multiple quadratic regression performed on the results of the CCD. Error bars were found larger than the coefficient value for factors related to the NBS amount

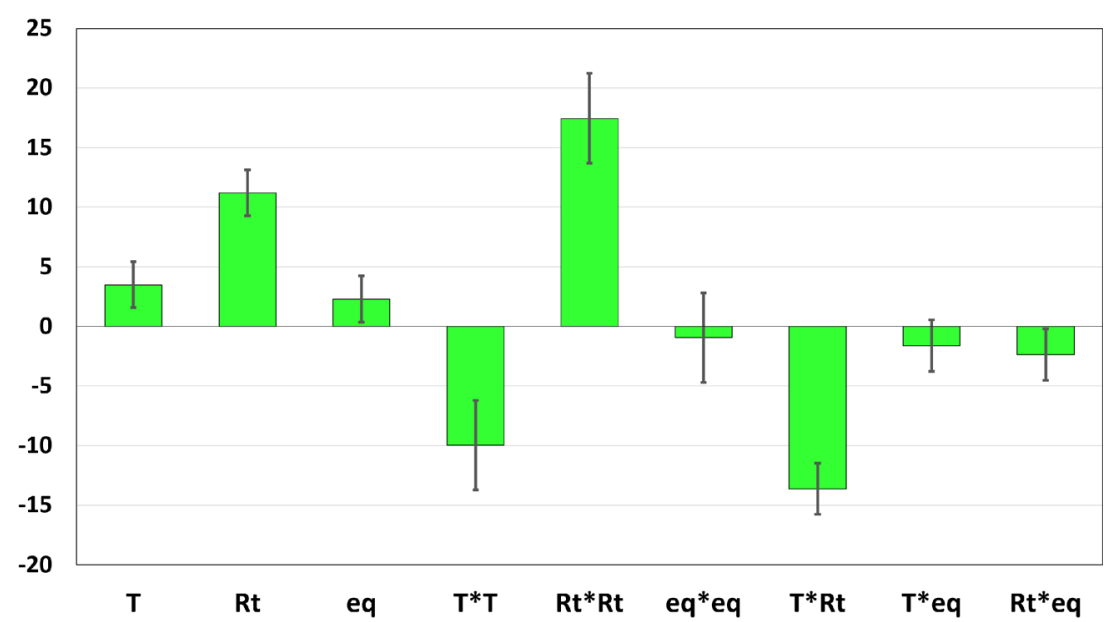

addition) and consumption of NBS (1.5 equivalents versus 3.0 equivalents).

\section{Experimental}

Materials and methods All reagents and solvents were commercially available and used as received. All reaction in continuous flow were carried out on a Vapourtec R-Series Flow Chemistry System, using PFA tubing (ID $1.0 \mathrm{~mm}$ ) and a heated mixer reactor with a PFA coil of $10 \mathrm{~mL}$ volume. Setting of the reaction parameters and sample collection were performed using the Flow Commander software. HPLC analyses were performed on a Shimadzu LC-2010C-HT instrument equipped with a Phenomenex Gemini $3 \mu \mathrm{C} 18$ column. DoE analysis of the data was performed using Minitab 17 Statistical Software. NMR spectra were recorded at $301 \mathrm{~K}$ on a Bruker Avance-300 MHz. The ${ }^{1} \mathrm{H}$ NMR spectra were referenced to the residual protiated impurity of $\mathrm{CDCl}_{3}$ $(7.26 \mathrm{ppm})$. Electrospray ionization mass spectrometry analysis was carried out on an Agilent Technologies LC/MSD Trap SL AGILENT instrument in positive mode with acetonitrile as mobile phase.

Synthesis of porphyrin 1 in batch conditions The reaction was carried out following a reported procedure. [24] $61.7 \mathrm{mg}$
$(0.10 \mathrm{mmol})$ of porphyrin 2 were dissolved in chloroform $(60 \mathrm{~mL})$. Pyridine $(1 \mathrm{~mL})$ was added and the mixture was heated to reflux. A solution of NBS $(53.7 \mathrm{mg}, 0.30 \mathrm{mmol})$ in chloroform $(60 \mathrm{~mL})$ was added dropwise over $3.5 \mathrm{~h}$. After additional $30 \mathrm{~min}$ of refluxing, the reaction mixture was quenched with acetone $(30 \mathrm{~mL})$. The HPLC analysis gave a composition of the reaction mixture as follows: $72 \%$ porphyrin $\mathbf{1}, 5 \%$ porphyrin 2 . The missing mass balance was assigned to a mixture of dibrominated porphyrin isomers.

Procedure for the DoE bromination experiments in continuous flow The flow reactions were performed using bottled reagent solutions. A stock chloroform solution of porphyrin $2(0.004 \mathrm{M})$ was prepared. An NBS solution in chloroform was freshly prepared each day and shielded from light with an aluminum foil. The concentration of the NBS solution depended on the number of NBS equivalents necessary for a given reaction (e.g. $0.006 \mathrm{M}$ solution when 1.5 equivalents were required). For each trial, $5 \mathrm{~mL}$ of the porphyrin solution and $5 \mathrm{~mL}$ of the NBS solution were withdrawn and mixed in a T-junction and flowed through a $10 \mathrm{~mL}$ internal volume coil reactor at the required temperature and flow rate. Reaction sampling was performed when the reagents concentration reached a steady state according to the dispersion model elaborated by the Flow Commander software. The samples were
Fig. 4 Contour plots of the yield (a) and selectivity (b) in $\mathbf{1}$ modeled through the regression equations resulting from the CCD analysis. NBS equivalents are kept at a constant value of 1.5
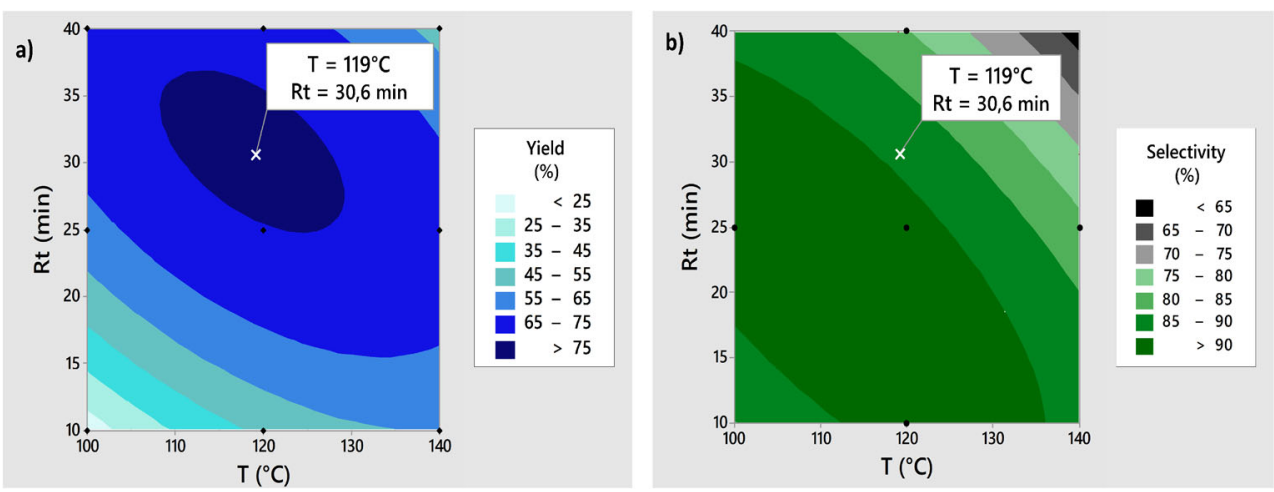
collected in vials containing a stirred $0.01 \mathrm{M}$ aqueous solution of $\mathrm{Na}_{2} \mathrm{CO}_{3}$ and $\mathrm{Na}_{2} \mathrm{~S}_{2} \mathrm{O}_{3}$ to quench unreacted NBS. The reaction mixture composition was determined by HPLC analysis.

\section{Continuous flow synthesis of porphyrin 1 on a $150 \mathrm{mg}$ scale} Following the above described general procedure, a $0.004 \mathrm{M}$ chloroform solution of porphyrin 2 and a $0.006 \mathrm{M}$ chloroform solution of NBS were mixed and flowed through the coil reactor at $118{ }^{\circ} \mathrm{C}$ with a residence time of $30.6 \mathrm{~min} .130 \mathrm{~mL}$ of the resulting reaction mixture were collected at the reactor outcome and quenched in a stirred $0.01 \mathrm{M}$ aqueous solution of $\mathrm{Na}_{2} \mathrm{CO}_{3}$ and $\mathrm{Na}_{2} \mathrm{~S}_{2} \mathrm{O}_{3}(100 \mathrm{~mL})$. The organic layer was separated, washed with water $(100 \mathrm{~mL})$, dried over $\mathrm{Na}_{2} \mathrm{SO}_{4}$ and evaporated to dryness. Porphyrin 1 was purified by flash chromatography on silica using 8:2 hexane/dichloromethane as eluent. A dark violet solid was obtained (128 mg, 73\%). NMR data are in accord with those reported in the literature, ${ }^{1} \mathrm{H}$ NMR $\left(300 \mathrm{MHz}, \mathrm{CDCl}_{3}\right) \delta$ 8.94-8.80 (m, 5H, $\left.\mathrm{H}_{\beta}\right), 8.77\left(\mathrm{~s}, 2 \mathrm{H}_{\beta}\right), 8.25-8.17\left(\mathrm{~m}, 6 \mathrm{H}, \mathrm{H}_{\mathrm{Ar}}\right)$, $8.10\left(\mathrm{~d}, J=6.8 \mathrm{~Hz}, 2 \mathrm{H}, \mathrm{H}_{\mathrm{Ar}}\right), 7.85-768\left(\mathrm{~m}, 12 \mathrm{H}, \mathrm{H}_{\mathrm{Ar}}\right),-2.84(\mathrm{~s}$, $2 \mathrm{H}, \mathrm{NH})$. ESI-MS(+) $m / z, 693[\mathrm{M}+1]$.

Supplementary Information The online version contains supplementary material available at https://doi.org/10.1007/s41981-020-00131-4.

Acknowledgments Open access funding provided by Università degli Studi di Padova within the CRUI-CARE Agreement. Financial support is gratefully acknowledged to Italian Ministry of Education, University and Research through the NExuS - Department of Excellence Program.

\section{Compliance with ethical standards}

Declarations The authors declare there is no conflict of interest.

Open Access This article is licensed under a Creative Commons Attribution 4.0 International License, which permits use, sharing, adaptation, distribution and reproduction in any medium or format, as long as you give appropriate credit to the original author(s) and the source, provide a link to the Creative Commons licence, and indicate if changes were made. The images or other third party material in this article are included in the article's Creative Commons licence, unless indicated otherwise in a credit line to the material. If material is not included in the article's Creative Commons licence and your intended use is not permitted by statutory regulation or exceeds the permitted use, you will need to obtain permission directly from the copyright holder. To view a copy of this licence, visit http://creativecommons.org/licenses/by/4.0/.

\section{References}

1. Gotico P, Halime Z, Aukauloo A (2020) Recent advances in metalloporphyrin-based catalyst design towards carbon dioxide reduction: from bio-inspired second coordination sphere modifications to hierarchical architectures. Dalton Trans 49(8):2381-2396

2. Percástegui EG, Jancik V (2020) Coordination-driven assemblies based on meso-substituted porphyrins: metal-organic cages and a new type of meso-metallaporphyrin macrocycles. Coord Chem Rev 407:213165

3. Damiano C, Sonzini P, Gallo E (2020) Iron catalysts with N-ligands for carbene transfer of diazo reagents. Chem Soc Rev 49(14):48674905

4. Paolesse R, Nardis S, Monti D, Stefanelli M, Di Natale C (2017) Porphyrinoids for chemical sensor applications. Chem Rev 117(4): 2517-2583

5. Wolf C, Bentley KW (2013) Chirality sensing using stereodynamic probes with distinct electronic circular dichroism output. Chem Soc Rev 42(12):5408-5424

6. Martynov AG, Safonova EA, Tsivadze AY, Gorbunova YG (2019) Functional molecular switches involving tetrapyrrolic macrocycles. Coord Chem Rev 387:325-347

7. Min Park J, Lee JH, Jang W-D (2020) Applications of porphyrins in emerging energy conversion technologies. Coord Chem Rev 407: 213157

8. Tian J, Huang B, Nawaz MH, Zhang W (2020) Recent advances of multi-dimensional porphyrin-based functional materials in photodynamic therapy. Coord Chem Rev 420:213410

9. Mavridis IM, Yannakopoulou K (2020) PorphyrinoidCyclodextrin assemblies in biomedical research: an update. $\mathrm{J}$ Med Chem 63(7):3391-3424

10. Supriya S, Shetti VS, Hegde G (2018) Conjugated systems of porphyrin-carbon nanoallotropes: a review. New J Chem 42(15): $12328-12348$

11. Alvarado DR, Argyropoulos DS, Scholle F, Peddinti BST, Ghiladi RA (2019) A facile strategy for photoactive nanocellulose-based antimicrobial materials. Green Chem 21(12):3424-3435

12. Merkaš S, Žinić M, Rein R, Solladié N (2019) Investigation by NMR spectroscopy of the structural characteristics of modified oligo-nucleotides with pendant porphyrins. J Porphyr Phthalocyanines 23:797-812

13. Chauhan P, Hadad C, Sartorelli A, Zarattini M, Herreros-López A, Mba M, Maggini M, Prato M, Carofiglio T (2013) Nanocrystalline cellulose-porphyrin hybrids: synthesis, supramolecular properties, and singlet-oxygen production. Chem Commun 49(76):8525-8527

14. Smith PT, Nichols EM, Cao Z, Chang CJ (2020) Hybrid catalysts for artificial photosynthesis: merging approaches from molecular, materials, and biological catalysis. Acc Chem Res 53(3):575-587

15. Di Carlo G, Biroli AO, Tessore F, Caramori S, Pizzotti M (2018) $\beta$ Substituted ZnII porphyrins as dyes for DSSC: a possible approach to photovoltaic windows. Coord Chem Rev 358:153-177

16. Sekaran B, Jang Y, Misra R, D'Souza F (2019) Push-pull Porphyrins via $\beta$-Pyrrole functionalization: evidence of excited state events leading to high-potential charge-separated states. Chem Eur J 25(56):12991-13001

17. Shen D-M, Liu C, Chen Q-Y (2005) A novel and facile Znmediated intramolecular five-membered cyclization of $\beta$ tetraarylporphyrin radicals from $\beta$-bromotetraarylporphyrins. Chem Commun 39:4982-4984

18. Vaccato L, Lanari D, Marocchi A, Strappaveccia G (2014) Flow approaches towards sustainability. Green Chem 16:3680-3704

19. Plutschack MB, Pieber B, Gilmore K, Seeberger PH (2017) The Hitchhiker's guide to flow chemistry. Chem Rev 117(18):1179611893

20. Steiner A, Williams JD, de Frutos O, Rincón JA, Mateos C, Kappe CO (2020) Continuous photochemical benzylic bromination using in situ generated $\mathrm{Br} 2$ : process intensification towards optimal PMI and throughput. Green Chem 22(2):448-454

21. Van Kerrebroeck R, Naert P, Heugebaert TSA, D'Hooghe M, Stevens CV (2019) Electrophilic Bromination in flow: a safe and sustainable alternative to the use of molecular bromine in batch. Molecules 24(11):2116 
22. Cantillo D, de Frutos O, Rincon JA, Mateos C, Kappe CO (2014) A scalable procedure for light-induced Benzylic Brominations in continuous flow. J Org Chem 79(1):223-229

23. Momo PB, Bellete BS, Brocksom TJ, de Souza ROMA, de Oliveira KT (2015) Exploiting novel process windows for the synthesis of meso-substituted porphyrins under continuous flow conditions. RSC Adv 5(102):84350-84355

24. Rhauderwiek T, Waitschat S, Wuttke S, Reinsch H, Bein T, Stock N (2016) Nanoscale synthesis of two Porphyrin-based MOFs with gallium and indium. Inorg Chem 55(11):5312-5319

25. Gao G-Y, Ruppel JV, Allen DB, Chen Y, Zhang XP (2007) Synthesis of $\beta$-functionalized Porphyrins via palladium-catalyzed carbon-heteroatom bond formations: expedient entry into $\beta$-chiral Porphyrins. J Org Chem 72(24):9060-9066

26. Murray PM, Tyler SNG, Moseley JD (2013) Beyond the numbers: charting chemical reaction space. Org Process Res Dev 17(1):4046

27. Bowden GD, Pichler BJ, Maurer A (2019) A Design of Experiments (DoE) approach accelerates the optimization of copper-mediated 18F-fluorination reactions of Arylstannanes. Sci Rep 9(1):11370

28. Mostarda S, Gür Maz T, Piccinno A, Cerra B, Banoglu E (2019) Optimisation by Design of Experiment of Benzimidazol-2-one synthesis under flow conditions. Molecules 24(13):2447

29. Callot HJ (1973) Bromuration de la meso-tetraphenylporphine.: Structure et reactivite des produits. Tetrahedron Lett 14(50):49874990
Publisher's note Springer Nature remains neutral with regard to jurisdictional claims in published maps and institutional affiliations.

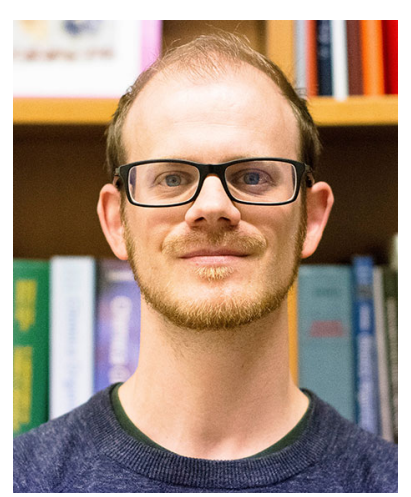

Paolo Zardi received his $\mathrm{PhD}$ under the supervision of Prof. Emma Gallo at the University of Milan in 2014. He pursued postdoctoral studies at the University of Padova (Prof. Giulia Licini’s group) and at the University of Rennes (France) under the supervision of Dr. Rafael GramageDoria. He currently holds a researcher position at the University of Padova and his interests are focused on the use of continuous flow systems in synthetic chemistry. 